GEORGETOWN SCIENTIFIC RESEARCH JOURNAL
Volume One Edition One February 2021

\title{
Biological and Physical Interactions at Local Ocean Scales: Coupled Systems
}

Victoria Boatwright, Baylor Fox Kemper, PhD. 


\title{
Biological and Physical Interactions at Local
}

\section{Ocean Scales: Coupled Systems}

\author{
Victoria Boatwright ${ }^{1}$ and Baylor Fox-Kemper ${ }^{2}$ \\ ${ }^{1}$ Department of Physics, Georgetown University, Washington DC, USA \\ ${ }^{2}$ Department of Earth, Environmental, and Planetary Sciences, Brown University, Providence RI, USA
}

E-mail: vb405@georgetown.edu

\begin{abstract}
Physical and biogeochemical processes that influence primary production set Earth's carbon and heat budgets. While these processes have long been the focus of research, high resolution models to investigate local phenomena have only recently been developed, and two-way coupling between oceanic physics and biology is only recently getting attention due to computational power. With these new developments, it is possible to study the mechanisms through which these processes interact at both global and regional scales to shape Earth's climate, which is the goal of this paper. This paper introduces oceanic physical phenomena at submesoscales to global scales - like mixed layer depth and turbulent structures - and the relationship of smaller scale events with biological factors. It discusses the implications of these relationships for primary production. After an introductory explanation of turbulence, primarily in the form of eddies and fronts, and the effects of internal instability and surface forcing, this paper emphasizes the contributions of those phenomena (turbulence, internal instability, and surface forcing) to vertical velocities and the influence of vertical transport on biology. Next, it introduces biogeochemical feedbacks, concerning both large scale population dynamics and increased absorption of radiation at the submesoscale, to consider their impacts on physical dynamics and regional climates. Finally, the paper compiles equations of irradiance and variables of significance, suggesting terms that could produce meaningful responses to variations in phytoplankton populations. The paper highlights the importance of understanding physical-biogeochemical relationships and suggests directions for future research, particularly areas related to global warming or abrupt climate change.
\end{abstract}

Keywords: turbulence, primary production, phytoplankton, submesoscale

\section{Introduction}

Oceans occupy $70 \%$ of the Earth's surface, accounting for the sequestration of $48 \%$ of carbon emissions, and its surface dwellers are responsible for roughly half of the atmospheric oxygen ${ }^{1}$. Marine primary producers are an integral component of the global carbon cycle, oxygen production, and marine ecosystems. Considering how marine primary production (the base of the food chain, organisms that synthesize organic compounds from carbon dioxide) accounts for twice the amount of carbon fixation performed by the open ocean $(90 \%$ of the ocean surface), it is important to understand the factors promoting the growth and abundance of 
marine producers ${ }^{2}$. The key marine primary producers are phytoplankton, which include a range of species with various characteristics, such as surface floaters, neutrally buoyant species, species dependent on iron for nitrogen fixing, and those that are $\mathrm{N}_{2}$-fixing ${ }^{3}$. While physical phenomena in the ocean are known to provide nutrients, light, and heat to plankton populations, the relationship between these physical phenomena and the abundance of marine life is still uncertain for two reasons. First, many of the interactions that impact biological abundance and spatial variability occur on the mesoscale (roughly $100 \mathrm{~km}$ or less) or even the submesoscale (often characterized as $0.1-10 \mathrm{~km}$ scale), depths at which resolution is currently an insurmountable computational cost to resolve, especially in two-way coupling schemes ${ }^{4}$. Second, the field is just beginning to understand the coupled feedback mechanisms of biogeochemical influences on physics. Coupled schemes are used in computational models to resolve the complex interactions between boundaries or systems; for example, ocean-atmosphere coupling was one of the first cases of relating two previously independent systems through heat flows, wind stress, and surface exchanges of molecules like carbon and oxygen ${ }^{5}$. In this paper, we demonstrate coupling between ocean physics (e.g. turbulence) and marine biogeochemistry (e.g. phytoplankton populations), which can be one-way (physics impacting biology, the more common approach to ocean models today) or two-way (physics impacts biology and biology influences physics). In doing so, this paper seeks to explain various biogeochemical-biological-physical feedbacks and their spatial scales as well as determine what parameterizations (variables or equations that can represent complex, often smallscale or unresolvable, interactions) can add to global or regional models in understanding the carbon cycle and heat exchanges. The discussion section details the impacts of global climate change and warming on submesoscale and mesoscale phenomena, identifying gaps in knowledge and potential consequences.

\section{Methods}

This review compiles studies that measure mixed layer depths, phytoplankton concentrations, mesoscale to submesoscale phenomena, ocean temperatures, and other physical events. Observational data in this paper are derived from several methods, including long-term hydrographic time-series, satellite imaging showing ocean color and sea surface height, in-situ measurements by Argo floats or ship-based measurements, and ocean reanalysis combining historical and computational models with observations. Ocean color indicates levels of chlorophyll-a, which is a proxy measurement for phytoplankton concentrations. Sea surface height is a proxy for eddies in the ocean, as cyclonic eddies tend to decrease surface height while anticyclonic eddies increase surface height. Models are used to determine variables of importance and predict future outcomes. This paper uses models across scales: local scales though the Large Eddy Simulation (LES), regional scales though the General Ocean Turbulence Model (GOTM) and Regional Ocean Modelling System (ROMS), and global scales though the Community Earth System Model (CESM) and MIT's General Circulation Model (MITgcm).

\section{Findings}

All complex dynamics discussed subsequently depend first on the fluid dynamics of the world's oceans. The Earth is a sphere covered in fluids, rotating about an axis. The winds in the atmosphere circulate about the globe and respond to pressure differentials, adding a shearing force to the ocean surface, which is then forced along with the wind's direction. Tidal currents and water density fluxes can also influence the direction of ocean surface currents. Next, we add continents and islands, and 
therefore coastlines, to the Earth. Due to hydrostatic pressure, ocean fluids will need to deflect in different directions in three dimensions as they cannot pile up on themselves along the shorelines. Since the fluids of the Earth's oceans are in a rotating frame, the fictitious Coriolis force is present in the Earth inertial frame, where the Coriolis force will deflect masses according to the cross product in

$$
f=-2 m(\boldsymbol{\Omega} \times \boldsymbol{v}),(1)
$$

where $\boldsymbol{\Omega}$ is Earth's rotation vector and $\boldsymbol{v}$ is the velocity of the mass of interest, or, broadly, to the right in the Northern Hemisphere and to the left in the Southern Hemisphere. This configuration will lead to an overall picture of surface currents, which circulate into gyres in the oceans, or smaller circulations in gulfs and bays. At smaller scales, surface currents will tend to circulate clockwise in the Northern Hemisphere and counterclockwise in the Southern Hemisphere. Incorporating density, masses of water with characteristic temperature and salinity (or isopycnals) will tend to sink or float (cold and high density waters will sink, whereas warm and less dense waters will float). This causes thermohaline circulation, which consists of deep waters with high temperature and salinity fluxes over their depth, allowing the flow of bottom waters to be circulated back into the surface currents over timescales of roughly a thousand years ${ }^{6}$. These differences in density and temperature can cause stratification, where two masses of water with different characteristics form an interface at which they have limited exchange. As deeper, colder waters often carry more nutrients due to sinking, this stratification is especially important when considering marine organisms as their resources will depend on the upwelling of these colder, nutrientrich waters.

With a background of the global currents, smaller scale phenomena add to the complexity of large scale circulations and ocean gyres. Mesoscale and submesoscale interactions create turbulence (the state of fluid motion that is chaotic and unsteady) in the form of eddies (smaller vortices), mixed layer restratification, fronts, and other instabilities $^{7-8}$. Figure 1 shows a global model of simulated submesoscale interactions with a $2 \mathrm{~km}$ resolution, revealing this turbulence across the globe. 
https://doi.org/10.48091/DNPR7287

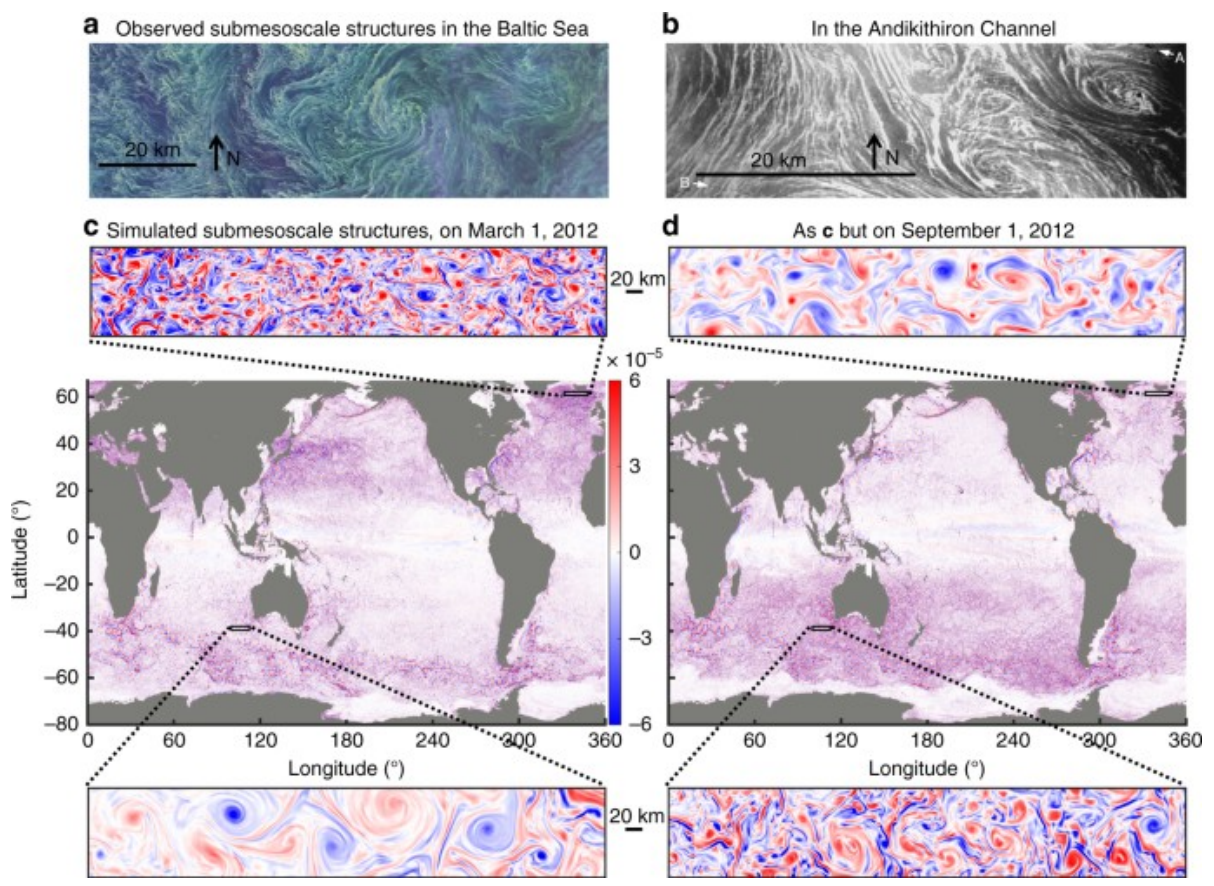

Figure 1. Visualization of global submesoscale phenomena and configuration, including eddies, front and filaments. a) Satellite image of cyanobacteria bloom using ocean color detecting chlorophyll-a concentrations as a proxy for bloom location. Shapes here indicate mesoscale and submesoscale eddies and fronts strongly affect biology. (Taken August 11, 2015, from NASA (https://landsat.visibleearth.nasa.gov/view.php?id=86449). b) Observation taken on October 7, 1984 with ship tracks labeled A and B. c, d) Simulated ocean turbulence at roughly $2 \mathrm{~km}$ resolution, expanded at local regions. Red indicates upwelling, or cyclonic eddies, and blue indicates downwelling, or anticyclonic eddies. c) shows simulation on March 1, 2012 (Northern Hemisphere winter/Southern Hemisphere summer) whereas d) shows simulation on September 1, 2012 (Northern Hemisphere summer/Southern Hemisphere winter). Taken from Su et. al, $2018^{9}$.

The mixed layer plays an important role in these interactions, as it absorbs and responds to the interactions at the surface. The mixed layer begins at the surface layer of the ocean, at the air-sea boundary, and continues throughout the region where temperature and salinity remain relatively uniform due to intense mixing of the upper ocean layer; once the temperature and salinity change drastically, the mixed layer ends, at which point the mixed layer is stratified from denser regions below. The mixed layer depth depends on both top mixing and bottom mixing ${ }^{10}$. Top mixing is driven by wind shear, waves, and buoyancy fluxes, while bottom mixing is driven by large turbulent eddies that mix denser fluid from below and shear instabilities that thicken the buoyancy interface and allow for mixing from turbulent eddies. Often, models and common perception indicate that warmer ocean surfaces yield shallower mixed layers and more stratified water beneath ${ }^{11}$. However, observational studies demonstrate that this relationship is more complex; stabilizing or destabilizing buoyancy forces may be the driver in regional mixed layer depth, as heating (cooling) can cause stabilizing (destabilizing) buoyancy forces leading to stratification (convective mixing and a deepening of the mixed layer). 
https://doi.org/10.48091/DNPR7287

Overall, observational studies of global patterns in foundational knowledge of how physical mixed layer depths show a broad correlation between surface temperature and mixed layer depth, as shown in Figure 2, although a comprehensive understanding of mechanisms shaping mixed layer depth is still under active research. With a phenomena form currents and circulation patterns, the study next investigates relationships at smaller scales and their potential impact on biology.

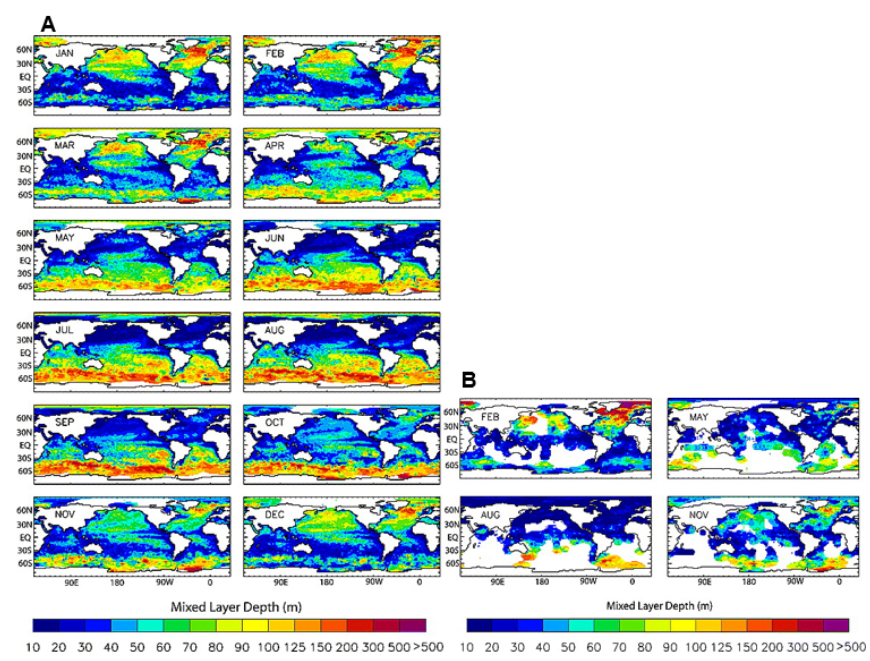

Figure 2. Global mixed layer depth climatology defined A) by temperature and B) by density. Criteria was based on computational inspection of profiles and time series data. Grid boxes are $2^{\circ}$ and smoothing was used to fill missing data. A) Mixed layer depth for individual profiles is determined using deviation from near-surface temperature at $10 \mathrm{~m}$ depth. A deviation of $0.2^{\circ} \mathrm{C}$ was used to mark the end of the mixed layer. B) Mixed layer depth is determined using deviation from near-surface density at $10 \mathrm{~m}$ depth. Density criterion is a difference of $0.03 \mathrm{~kg} / \mathrm{m}^{3}$ from near-surface density, indicating the measurement is outside of well-mixed region. Figures adapted from de Boyer Montégut et. al, 2004

To localize biologically productive regions in the ocean, the basic needs of phytoplankton populations must first be identified. We know phytoplankton (marine plants that perform photosynthesis) growth depends on light and nutrients. As most phytoplankton have limited control over their motion, populations predominantly flow with currents, and so physical phenomena dictate whether they have access to their basic needs. A critical disjunction between nutrient and light availability prevails; while sunlight is abundant at the surface and photosynthetically available radiation decreases exponentially with depth, nutrients are increasingly abundant in deep waters due to their sinking tendencies and storage in more dense waters. Similarly, while sunlight is abundant in subtropical regions, these regions tend to be depleted of nutrients as they tend to have shallow mixed layers that do not reach to the nutrients stored below. On the other hand, subpolar regions have deep mixed layers that can incorporate nutrients from colder, deeper waters (often reincorporated to the surface from convective mixing from the bottom), but a lack of sufficient light to support yearlong growth. This spatial consequence is shown in Figure $3^{13}$. For this reason, upwelling regions (where cold, nutrientdense water is pumped to the surface from deeper 
https://doi.org/10.48091/DNPR7287

waters by the topography of continental shelves) tend to be highly productive with increased levels of

$$
\text { phytoplankton }
$$

abundance

compared

to
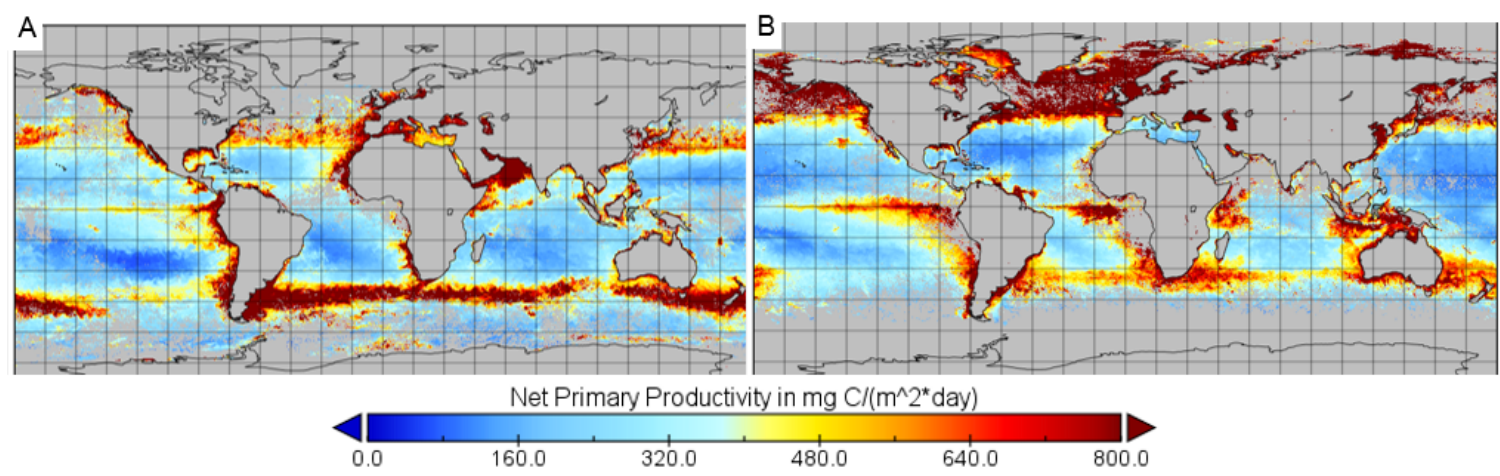

Figure 3. Observational measurements of global primary production. Satellite data from NOAA's Aqua MODIS on Chlorophyll a, incident visible surface irradiance, and sea surface temperature. Scale from 0 to $800 \mathrm{mg} \mathrm{C} /\left(\mathrm{m}^{2}\right.$ day $)$, excluding extreme highs from scale for visualization. Observations from A) January 16, 2019 (Southern Hemisphere summer) and B) July 16, 2019 (Northern Hemisphere summer). Graphed by author.

Here, it will be noted that this broad confluence of light and nutrients is not the only effect on localization of primary production. Zooplankton grazing, diversity within phytoplankton species allowing for optimizations in different environments, and other factors will influence the net growth of phytoplankton populations. With the general importance of vertical transport in mind, the study turns to investigate small scale phenomena that can promote vertical velocities and fluxes of isopycnals. Focusing in on turbulence at the mesoscale and submesoscale, there are a number of mechanisms that impact vertical velocities in a more substantial way than that of global, large scale circulations. Internal instabilities and surface forcing enhance or suppress submesoscale dynamics ${ }^{8}$. Eddies can form at scales of $0.1-100 \mathrm{~km}$, created from anomalies in temperature and salinity, and carry rotational kinetic energy that can transport heat, salt, carbon, and nutrients in the horizontal and vertical planes ${ }^{14}$. Eddies also tend to stratify the mixed layer, which has been shown to initiate blooms in subpolar regions by keeping phytoplankton populations in upper regions with increased light exposure ${ }^{15}$. Fronts, produced from horizontal gradients of buoyancy (or variations in static pressure causing drag and lift forces), can form boundaries between isopycnals. These cause a crossfront ageostrophic secondary circulation to reach thermal wind balance, producing vertical velocities, as shown in Figure 4. The vertical velocities of fronts may support the transport of nutrients up into the euphotic zone where phytoplankton can access them, but they can also drive phytoplankton down away from the sunlight into lower levels without photosynthetically available radiation ${ }^{13}$. 


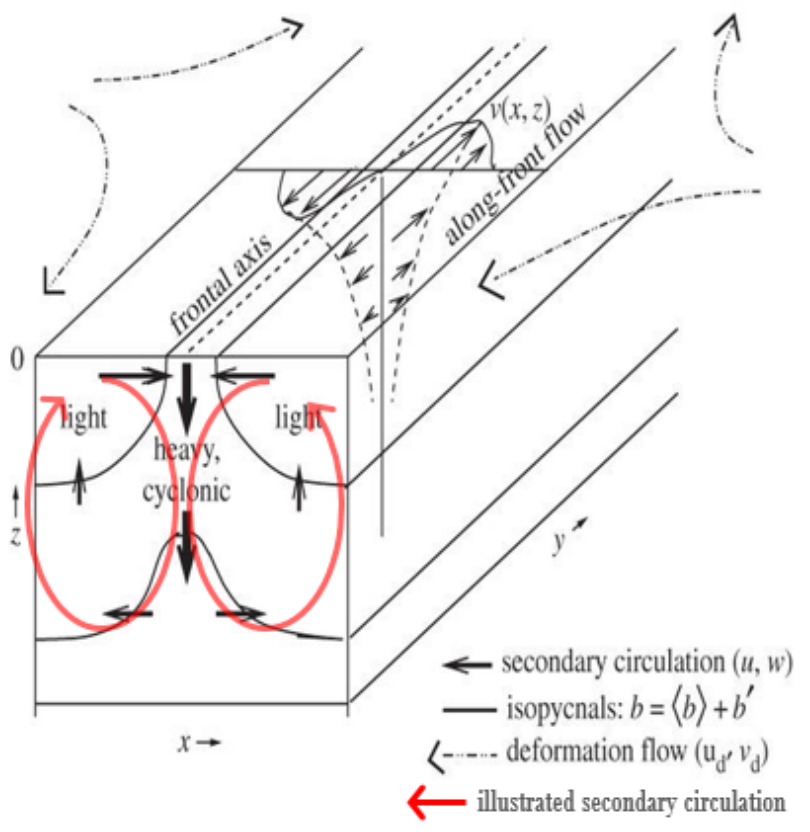

Figure 4. Depiction of submesoscale surface front configuration and the vertical velocities in frontogenesis. The along-front flow is mostly geostrophic, while the secondary circulation (in bold black and red arrows) is ageostrophic and acts to balance the system into thermal wind balance. Figure adapted from Figure 5 in McWilliams $2016^{16}$.

However, the impact of either of these outcomes depends on frontal depth; while a deep front can access the nutricline (nutrient-rich layer often beneath the mixed layer) and upwell nutrients, a shallow front may not reach past the mixed layer and therefore have minimal effect to primary production near the surface. Further potential impact for submesoscale processes on phytoplankton populations and spatial distribution is suggested by the similarity in timescale. Phytoplankton variability develops over the course of days, aligning well with the submesoscale timescales that last roughly days. This is illustrated by the mathematical relationship between timescale and length scale, given the timescale approximation of:

$T_{S}=\frac{L_{S}}{U}$,

where $U$ is advective velocity, typically $0.1 \mathrm{~m} / \mathrm{s}$, and $L_{s}$ for submesoscale events is typically $1 \mathrm{~km}^{8}$. In subtropical regions with shallow mixed layers, these local phenomena could be the only contribution of vertical velocities, yielding variability in regions further from the coast and allowing primary production. Nevertheless, the effect of submesoscale influences are up for debate. Some studies argue that the stirring and redistribution of the water column on the submesoscale level may not have a significant effect on global phytoplankton budgets and dynamics due to fewer submesoscale interactions in subtropical regions compared to subpolar regions, which already have sufficient nutrients in the mixed layer ${ }^{13}$. Evaluating the regions with shallow mixed layers where mesoscale and submesoscale interactions have potential to change phytoplankton populations should be incorporated into regional models through physical-biological coupling. This will optimize predictions of carbon cycling and of higher trophic marine populations that depend on primary production for regional fisheries. 
After investigating physical mechanisms that affect biology, it is critical to understand how biological factors can have an influence on oceanic physics and at what scale. Light can have impacts on ocean fluids by increasing sea surface temperature (SST) and affecting energy fluxes. In clear water, the shortwave radiation absorbed into the upper ocean is uniform, depending on

$$
I(z)=I_{0} \exp \left\{\frac{Z}{\eta}\right\}
$$

where $I_{0}$ is the albedo-corrected surface radiation, $\mathrm{z}$ is the depth, and $\eta$ is the attenuation length, or a manipulation of the absorption coefficient of seawater ${ }^{17}$. However, waters are not all crystal clear, and varying levels of clarity must be accounted for. Jerlov defined five types of oceanic water clarity in 1968, ranging from clear to murkier, dirtier waters, which have been named Jerlov types ${ }^{18}$. Incorporating these different Jerlov types affects the irradiance into the ocean, which changes the equation to become:

$$
I(z)=I_{0}\left[a \exp \left\{\frac{z}{\eta_{1}}\right\}+(1-a) \exp \left\{\frac{z}{\eta_{2}}\right\} B(z)\right],
$$

in which the first term concerns the red part of the light spectrum, the second term concerns the bluegreen part, $a$ is a dimensionless weighting parameter, and $\eta_{1}$ and $\eta_{2}$ are attenuation lengths. All of these parameters will change depending on the Jerlov type ${ }^{19}$. The $B(z)$ term represents bioturbidity, which depends on phytoplankton concentrations and detritus (dead particulate organic matter) concentration, as

$$
B(z)=\exp \left(-k_{c} \int_{z}^{0} P^{i}(z)+D(z) d z\right)
$$

where $k_{c}$ is the attenuation constant for shelf shading, $\mathrm{P}$ is phytoplankton concentrations, $\mathrm{i}$ is the index of different plankton species, and D is the detritus concentration ${ }^{20}$. Equation 5 illustrates the additional absorption provided by biological presence, the importance of which is shown by the impact of the irradiance curve on physical factors:

$$
\partial_{t} T-v^{\prime} \partial_{z z} T+\partial_{z}\left\langle w^{\prime} T^{\prime}\right\rangle=\frac{\partial_{z} I}{c_{P} \rho_{0}},
$$

where $\mathrm{T}$ denotes temperature, $v^{\prime}$ represents molecular diffusivity of heat, $w^{\prime}$ is the vertical component of velocity, $c_{P}$ is the specific heat of seawater, and $\rho_{0}$ is the reference density of seawater $^{19}$. Equation 6 highlights the aforementioned relationship between light (irradiance) and temperature in the ocean. An increase in absorbed radiation into the ocean by biological presence impacts the potential heat storage in the ocean, which in turn affects temperature differentials and triggers physical responses of turbulence or other events. We can make simple calculations to show the magnitude of the effect of biology using Jerlov types as proxies for high biological presence: We can calculate the effect of a typical level of solar radiation $\left(500 \mathrm{~W} / \mathrm{m}^{2}\right)$ in different Jerlov water types, the murkier water (Jerlov Type III) representing regions with high phytoplankton abundance and the clear water (Jerlov Type I) void of organisms. In a simple scheme without mixing, we use Equations 4 and 6 to evaluate the change in temperature over the depth in different Jerlov types. In this basic scheme where we assume the water stays in place, the magnitude of the warming across our mixed layer in Type III is greater by roughly $0.5{ }^{\circ} \mathrm{C}$ over time compared to Type I (Figure 5). However, the extent of this impact remains unclear as ocean waters do in fact mix; there is clearly missing information, as Havg in Figure 5 has a greater change in temperature, which shows the change in temperature in a well-mixed water column using the equation:

$$
\frac{d T}{d t}=\frac{I_{0}}{c_{P} \rho_{0} H}
$$


where $\mathrm{H}$ is the mixed layer depth. The increased shows that our simple calculation is only the temperature change in the mixed layer scheme beginning of the story.

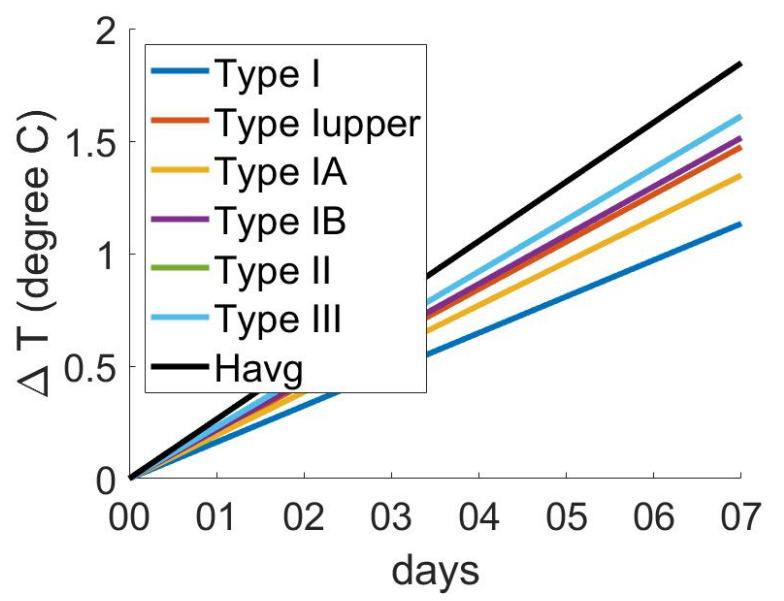

Figure 5. Change in temperature between the surface and bottom of the mixed layer for different Jerlov Types. Equation 4 was used across $100 \mathrm{~m}$ depth from the surface to evaluate irradiance over ocean depth. Equation 6 was used to convert irradiance to temperature change over the timeframe of a week. Mixed layer depth was set to $40 \mathrm{~m}$ depth arbitrarily and Equation 7 was used to calculate the temperature change. The difference between Type III (proxy for high biological presence) and Type I (clear water) after 7 days is $0.48^{\circ} \mathrm{C}$.

To fully understand the magnitude of biology's impact of heat storage in the ocean, these equations must be incorporated into small-scale models or parameterized into larger or global models. Using two-way coupled models between physics and biology, the potential physical outcomes of these additional temperature differentials could be detected. Studies have shown that an increased abundance of surface marine organisms like phytoplankton or other floaters causes both the surface albedo (amount of light that is reflected back from Earth) and absorption to be increased while momentum input from shear stress from surface winds causes it to be decreased ${ }^{20}$. Furthermore, research has indicated that for surfacing floating phytoplankton species, marine populations' effects of increasing absorption and reducing wind drag would outweigh the effects of an altered albedo. In regions with shallow mixed layer depth, it could be especially important to parameterize this biogeochemical-physical relationship at frontal events, as a front often develops higher biological concentrations on the side of higher density. This could theoretically lead to differential heating, changing the dynamics of the front and affecting feedback loops ${ }^{21}$. This phenomenon could have implications for marine ecosystems, as fisheries have long known that higher trophic marine organisms like fish populations, whales, and seabirds congregate near oceanic fronts, yet this occurrence still lacks comprehensive understanding in its relationship to physical oceanography ${ }^{21}$. Biogeochemical-physical coupling could help inform regional scales of heat capacity, as it has already been shown that including submesoscale interactions significantly and consistently increase upward heat transport and warms the sea surface up to $0.3^{\circ} \mathrm{C}$ at a global scale ${ }^{9}$. 
Incorporating irradiance parameterizations into climate models could affect regional carbon budgets by changing positive feedback loops of plankton populations and other unknown physical responses ${ }^{20}$.

\section{Discussion}

With an understanding of various physical and biogeochemical processes that could be parameterized, this study discussed the potential outcomes and open questions for investigation. As mentioned, mesoscale and submesoscale processes have potential to impact primary production which has serious implications for higher trophic ecosystem health. This in turn influences human economies through fisheries, tourism, and other ecosystem services. Potential heat storage in the ocean, and the coupled effects of phytoplankton growth in relation to temperature changes, is also a relevant area of study that requires further research. In terms of biological studies, future research must aim to study different species and diversity within phytoplankton populations, as abrupt climate changes could have tremendous effects on biodiversity, food chain dynamics, and spatial distributions and variations across a global scale.

Considering the looming threat of global warming, it is critical to investigate how these processes will respond to increased sea surface temperatures (SST) and higher levels of anthropogenic carbon. Some studies indicate that higher SST will lead to a more stratified ocean, decreasing nutrient fluxes from the nutricline or shallowing the mixed layer into more subpolar regions $^{22}$. However, more frequent and stronger storms would increase turbulence in the ocean, providing vertical fluxes and nutrients ${ }^{23}$. While global and regional models are equipped to make predictions on specific changes in turbulence and local circulations, incorporating biological coupling into these models and understanding the various outcomes in relation to primary production require further research until they can be wellunderstood.

\section{Acknowledgements}

The author wishes to thank Baylor Fox-Kemper and Leah Johnson for their research collaborative methods and inspiring this research project. The author acknowledges the helpful advice from Thomas Cronin, Deven Malone, Chris Scholz, and Joseph Feldblum. Particular gratitude goes to William Boatwright and Louisa Boatwright for encouraging and supporting the author's studies.

\section{References}

1. Falkowski, P. (2012). Ocean science: the power of plankton. Nature, 483(7387), S17-S20. https://doi.org/10.1038/483S17a

2. Martin, J. H., Knauer, G. A., Karl, D. M., \& Broenkow, W. W. (1987). VERTEX: carbon cycling in the northeast Pacific. Deep Sea Research Part A. Oceanographic Research Papers, 34(2), 267-285.

https://www.whoi.edu/cms/files/MartinKnauer Karl CarbonVertex DSR1987 52929.pdf

3. Gargett, A., \& Marra, J. O. H. N. (2002). Effects of upper ocean physical processes (turbulence, advection and air-sea interaction) on oceanic primary production. The sea, 12, 1949.

http://www.ccpo.odu.edu/ gargett/TheSeaCh0 2.pdf

4. Fox-Kemper, B. (2018). Notions for the motions of the oceans. New Frontiers in Operational Oceanography, 27-74. https://doi.org/10.17125/gov2018.ch02

5. Bjerknes, J. (1964). Atlantic air-sea interaction. In Advances in geophysics (Vol. 10, pp. 1-82). Elsevier. https://doi.org/10.1016/S00652687(08)60005-9

6. Boccaletti, G. (2005). Timescales and dynamics of the formation of a thermocline. Dynamics of atmospheres and oceans, 39(1-2), 21-40. 
https://doi.org/10.48091/DNPR7287

https://doi.org/10.1016/j.dynatmoce.2004.10.0 $\underline{10}$

7. Boccaletti, G., Ferrari, R., \& Fox-Kemper, B. (2007). Mixed layer instabilities and restratification. Journal of Physical Oceanography, 37(9), 2228-2250. https://doi.org/10.1175/JPO3101.1

8. Mahadevan, A. (2016). The impact of submesoscale physics on primary productivity of plankton. Annual review of marine science, 8 , 161-184. https://doi.org/10.1146/annurevmarine-010814-015912

9. Su, Z., Wang, J., Klein, P., Thompson, A. F., \& Menemenlis, D. (2018). Ocean

submesoscales as a key component of the global heat budget. Nature communications, 9(1), 1-8. https://doi.org/10.1038/s41467-018-02983-w

10. Kantha, L., Clayson, CA. (2003). Ocean Mixed Layer. In: Boundary Layers: Elsevier Science, 291-298.

https://curry.eas.gatech.edu/Courses/6140/ency /Chapter11/Ency Atmos/BL Ocean Mixed

Layer.pdf

11. Somavilla, R., González-Pola, C., \& Fernández-Diaz, J. (2017). The warmer the ocean surface, the shallower the mixed layer. How much of this is true?. Journal of Geophysical Research: Oceans, 122(9), 7698-7716. https://doi.org/10.1002/2017JC013125

12. de Boyer Montégut, C., Madec, G., Fischer, A. S., Lazar, A., \& Iudicone, D. (2004). Mixed layer depth over the global ocean: An examination of profile data and a profile-based climatology. Journal of Geophysical Research: Oceans, 109(C12). https://doi.org/10.1029/2004JC002378

13. Lévy, M., Franks, P. J., \& Smith, K. S. (2018). The role of submesoscale currents in structuring marine ecosystems. Nature communications, 9(1), 1-16. https://doi.org/10.1038/s41467-018$\underline{07059-3}$
14. Griffies, S. M., Winton, M., Anderson, W. G., Benson, R., Delworth, T. L., Dufour, C. O., ... \& Zhang, R. (2015). Impacts on ocean heat from transient mesoscale eddies in a hierarchy of climate models. Journal of Climate, 28(3), 952-977. https://doi.org/10.1175/JCLI-D-14$\underline{00353.1}$

15. Mahadevan, A., D’asaro, E., Lee, C., \& Perry, M. J. (2012). Eddy-driven stratification initiates North Atlantic spring phytoplankton blooms. Science, 337(6090), 54-58. https://doi.org/10.1126/science. 1218740

16. McWilliams, J. C. (2016). Submesoscale currents in the ocean. Proceedings of the Royal Society A: Mathematical, Physical and Engineering Sciences, 472(2189), 20160117. https://doi.org/10.1098/rspa.2016.0117

17. Paulson, C. A., \& Simpson, J. J. (1977). Irradiance measurements in the upper ocean. Journal of Physical Oceanography, 7(6), 952-956. https://doi.org/10.1175/15200485(1977)007<0952:IMITUO>2.0.CO;2

18. Jerlov, N. G. (2014). Optical oceanography.

19. Burchard, H., Bolding, K., Kühn, W., Meister, A., Neumann, T., \& Umlauf, L. (2006). Description of a flexible and extendable physical-biogeochemical model system for the water column. Journal of Marine Systems, 61(34), 180-211.

https://doi.org/10.1016/j.jmarsys.2005.04.011

20. Sonntag, S., \& Hense, I. (2011). Phytoplankton behavior affects ocean mixed layer dynamics through biological-physical feedback mechanisms. Geophysical Research Letters, 38(15). https://doi.org/10.1029/2011GL048205

21. Olson, D. B., Hitchcock, G. L., Mariano, A. J., Ashjian, C. J., Peng, G., Nero, R. W., \& Podestá, G. P. (1994). Life on the edge: marine life and fronts. Oceanography, 7(2), 52-60. https://doi.org/10.5670/oceanog.1994.03 
https://doi.org/10.48091/DNPR7287

22. Yamaguchi, R., \& Suga, T. (2019). Trend and variability in global upper-ocean stratification since the 1960s. Journal of Geophysical Research: Oceans, 124(12), 8933-8948. https://doi.org/10.1029/2019JC015439

23. Schultze, L. K., Merckelbach, L. M., \& Carpenter, J. R. (2020). Storm-induced turbulence alters shelf sea vertical fluxes. Limnology and Oceanography Letters, 5(3), 264-270. https://doi.org/10.1002/1ol2.10139 


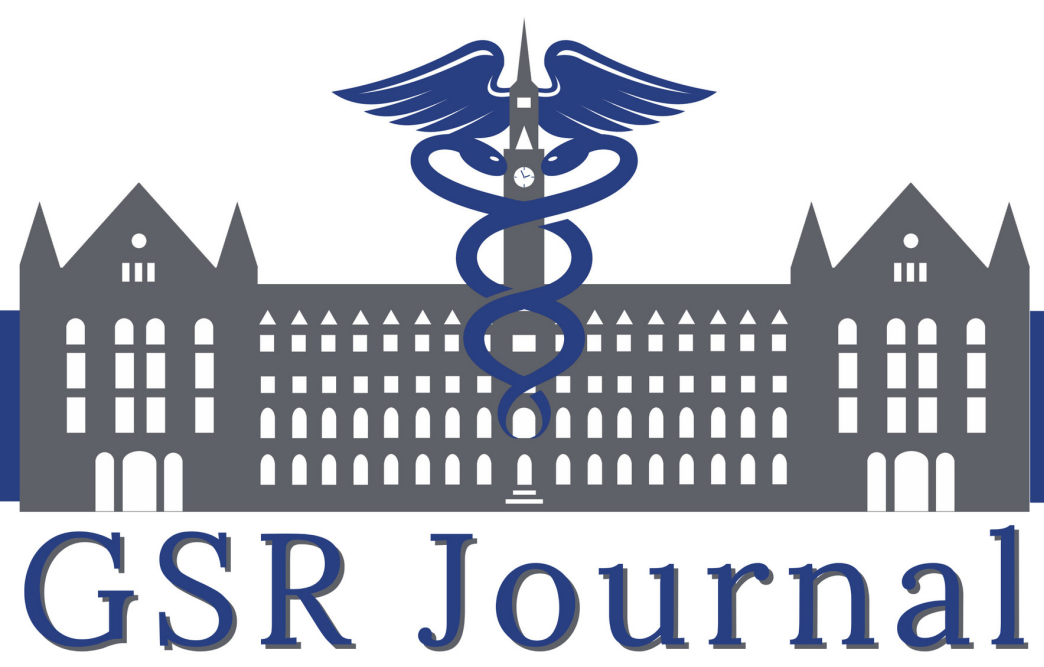

Georgetown Scientific Research Journal 